\title{
THE STRENGTH OF FRICTION STIR WELDED AND FRICTION STIR PROCESSED ALUMINIUM ALLOYS
}

\author{
M.J. Starink ${ }^{1}$, A. Deschamps ${ }^{2}$, S.C. Wang ${ }^{1}$ \\ ${ }^{1}$ Materials Research Group, School of Engineering Sciences, University of Southampton, \\ Southampton SO17 1BJ, United Kingdom \\ ${ }^{2}$ SIMAP, INPGrenoble-CNRS-UJF BP 75, 38402 St Martin d'Hères Cedex, France
}

\begin{abstract}
Local strength of friction stir (FS) welds and FS processed aluminium alloys in heat treatable aluminium alloys is dominated by precipitation hardening. Strengthening due to stored dislocations is generally limited to $40 \mathrm{MPa}$, and grain size strengthening is generally less than $10 \mathrm{MPa}$. Local crystallographic texture can cause yield strength variation on the order of 5\%. Published models for strengthening of FS welds make a range of simplifying assumption which can cause uncertainties in the predictions of up to 50MPa. Possible improvements are explored.
\end{abstract}

Keywords: transmission electron microscopy (TEM); aluminium alloys; recrystallized microstructure; phase transformations; yield strength

\section{Introduction}

In friction stir (FS) welding [1,2], the rotating tool causes local changes in the welded material due to both the mechanical deformation and the heat generated by friction [3,4]. The heat is conducted into the alloy leading to a zone in which the micro- (and nano) structure of the material is significantly changed due to mechanical work and increased temperature. In welding convention, the zones are identified as the heat affected zone (HAZ) and the thermo-mechanically affected zone (TMZ). These broad terms can only hint at the wide range of complex and interlinked processes that occur in FS welding (and other FS processing). In effect, in a single FS weld an extraordinarily wide range of processes occur. Recovery, recrystallisation, precipitation, dissolution, and re-precipitation can occur, whilst also partial melting and solidification can be possible in certain conditions. These processes occur within a short time interval of typically a few seconds in zones as small as a few hundreds of microns to a few $\mathrm{mm}$ wide. A full understanding of the process requires models of processes occurring over a scale of millimetres (e.g., the thermomechanical deformation around the rotating pin) down to the subnanometer scale, where formation of small atom clusters (GP zones) can have a strong influence on strength in heat-treatable alloys [5,6].

Prediction of strength of FS welds requires 3 main models: i) a model for heat generation and heat diffusion, ii) a model for evolution of the nano/microstructure as a function of temperature and deformation, and iii) a model for strength as a function of the nano/microstructure. We will here focus on ii and iii, as models for heat generation and diffusion, which are in most cases 3D finite element models, will be discussed elsewhere in this volume. Whilst this contribution will focus for the most part on FS welds, many of the principles are applicable to FS processing. 


\section{The mechanisms of strengthening in FS welds and FS processed materials}

In FS welds and FS processed materials, all the known mechanisms of strengthening of polycrystalline alloys can play a role. The mechanisms for increasing the critical resolved shear stress (CRSS) of the slip planes are:

A - precipitation strengthening, this can include precipitates detectable in transmission electron microscopy as well as nanoscale precipitates

$\mathrm{B}$ - solution strengthening

$\mathrm{C}$ - dislocation strengthening

The response to stress of the polycrystal will depend on the CRSS and factors such as:

D - local grain size; if the grain size is sufficiently small this will lead to grain boundary (GB) strengthening

E - crystallographic orientations of grains with respect to each other, i.e., the crystallographic texture.

Each of these factors (A-E) can have a substantial influence on strength. However, in heat treatable alloys strength is generally dominated by precipitation strengthening (A), e.g., in 7xxx ( $\mathrm{Al}-\mathrm{Zn}-\mathrm{Mg}-\mathrm{Cu}$ ) alloys precipitation strengthening can account for 500 to $600 \mathrm{MPa}$, typically 70 to $80 \%$ of the alloy's strength [7]. As we will see below, the strengthening due to mechanisms C-E add up to less than 100 $\mathrm{MPa}$. This shows that in welds of heat treatable alloys the precipitation reaction is dominant in determining the weld strength. The importance of precipitates is illustrated by the TEM work on a 2024 FS weld in Fig. 1 showing drastic changes in precipitates responsible for hardening as a function of the distance to the weld centre, whilst also dislocation densities are seen to change. The strength contributions of precipitates have been analysed in a number of works. To obtain accurate models for heat treatable alloys, at least two precipitates need to be included of which the lower stability type is generally clusters / GP zones (these two terms often indicate the same type of precipitate), and the higher stability one is a (near) equilibrium phase [3]. The two precipitate types will strengthen the alloy through two different mechanisms, and hence the term two precipitate- two mechanism model has been applied to the corresponding model $[3,5]$.

For alloys in which the elastic and plastic inhomogeneity of crystals is limited, the superposition of the different strengthening effects can be approximated well as [5,7]:

$$
\sigma_{\mathrm{y}}=\Delta \sigma_{\mathrm{gb}}+M \tau_{\mathrm{tot}}=\Delta \sigma_{\mathrm{gb}}+M\left[\Delta \tau_{0}+\Delta \tau_{\mathrm{ss}}+\left(\Delta \tau_{\mathrm{D}}^{2}+\Delta \tau_{\mathrm{ppt}}^{2}\right)^{1 / 2}\right]
$$

where $\Delta \sigma_{\mathrm{gb}}$ is the strength increment due to the grain boundaries, $M$ is a crystallographic orientation factor (often termed the Taylor factor) related to texture and the orientation of the specimen, $\tau_{\text {tot }}$ is the CRSS of the grains, and the various contributions to the CRSS are defined in Table 1.

The section of the TMAZ that has seen temperatures that are sufficient for recrystallisation, will have a grain structure that is caused by the recrystallisation or dynamic recrystallisation process. GB strengthening of a fully or partially recrystallised metal can be approximated well by [8]:

$$
\Delta \sigma_{g b}=\alpha_{2} G b\left[\left(1-f_{\operatorname{Re} X}\right)\left(\frac{1}{\delta}\right)+f_{\operatorname{Re} X}\left(\frac{1}{D}\right)\right]
$$


Table 1 Different hardening contributions to the CRSS of grains

\begin{tabular}{ll} 
Intrinsic strength of pure metal & $\Delta \tau_{0}$ \\
Solid solution strengthening & $\Delta \tau_{\mathrm{ss}}$ \\
Dislocation strengthening & $\Delta \tau_{\mathrm{D}}$ \\
Precipitation strengthening & $\Delta \tau_{\mathrm{ppt}}$ \\
\hline
\end{tabular}
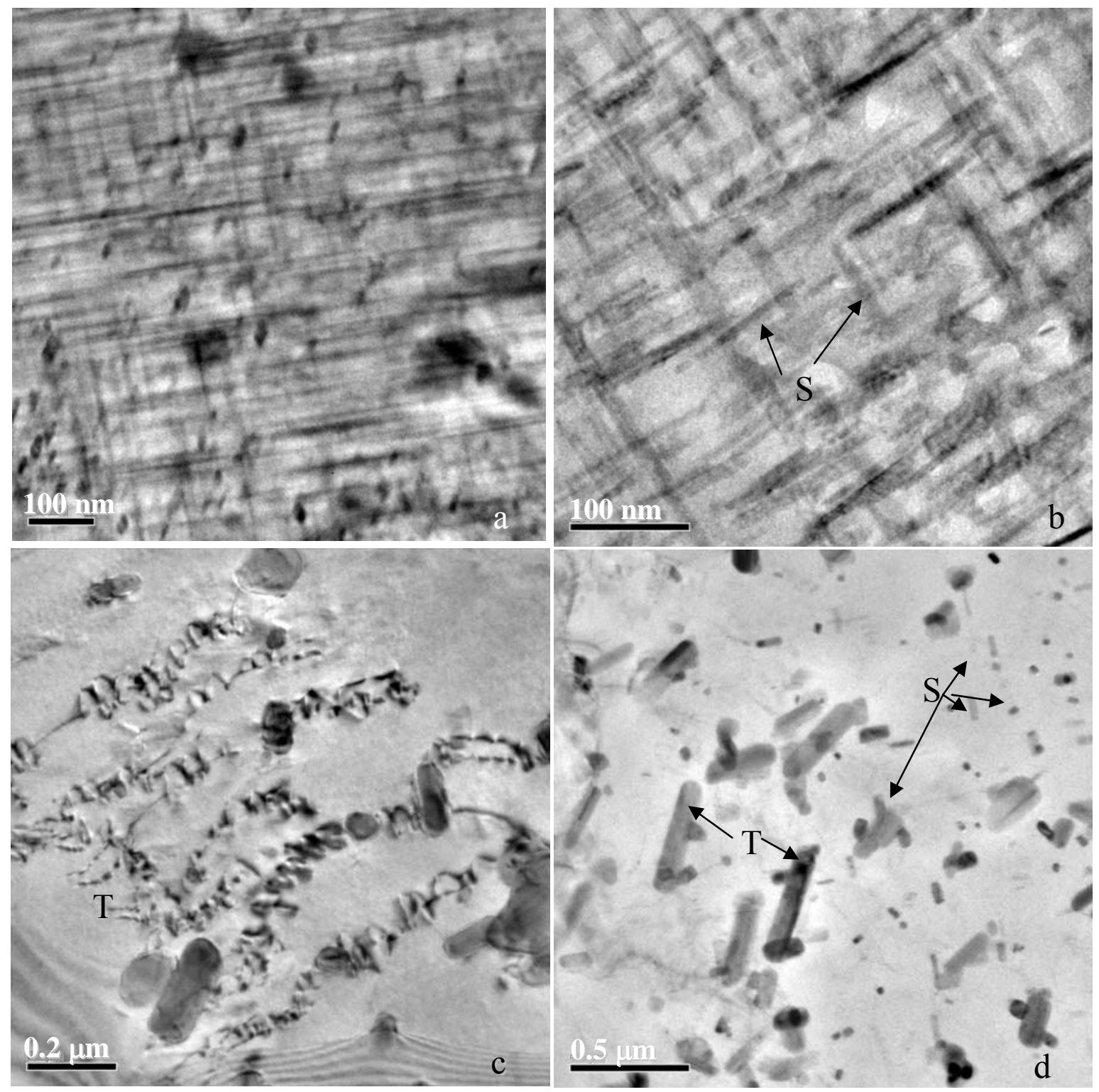

Fig. 1 TEM images of an FS weld of a 3mm T3 2024 (Al-Cu-Mg) with a T6 2024 plate. (a). Advancing side (originally T6) 40 mm away from weld centre. The needle or laths are $\mathrm{S}$ $\left(\mathrm{Al}_{2} \mathrm{CuMg}\right)$ phase with cross-section of 5-8nm in diameter; (b). Advancing side $3 \mathrm{~mm}$ away from the centre; $\mathrm{S}$ phase coarsened in comparison with originally T6 condition (c). Weld centre, S phase dissolved; T (Al-Cu-Mn) phase is the only remaining precipitate resolvable in TEM (d). Retreating side $3 \mathrm{~mm}$ (originally T3) away from the centre; a low density of coarse $\mathrm{S}$ phase is seen. 
where $f_{\mathrm{ReX}}$ is the recrystallised volume fraction, $\delta$ is the (sub-)grain size or cell size in the unrecrystallised part of the material, $\alpha_{2}$ is a constant (typically equalling 2 for Al alloys [9]) and $D$ is the grain size of the recrystallised part of the material. Cell size and/or grain size in FS welds (and FS processed materials) are typically 3 to $15 \mu \mathrm{m}$ (see e.g., [2,10,11,12]), with the smaller grain sizes generally being related to the presence of second phase particles which impede grain growth. The grain size can be further refined by $\mathrm{Zr}$ additions to about $1.5 \mu \mathrm{m}$ [13], and recent work on $\mathrm{Al}$ and $\mathrm{Mg}$ alloys has shown that a grain size of 100-300 nm can be attained by FS processing when rapid cooling using a heat sink is employed $[14,15,16]$. The latter equation predicts a strength increment of $15 \mathrm{MPa}$ for a 1 $\mu \mathrm{m}$ grain size. Thus, GB strengthening is generally negligible, and for medium to high strength alloys GB strengthening will be swamped by other strengthening factors [17], unless especially high cooling rates lead to nanosized grains.

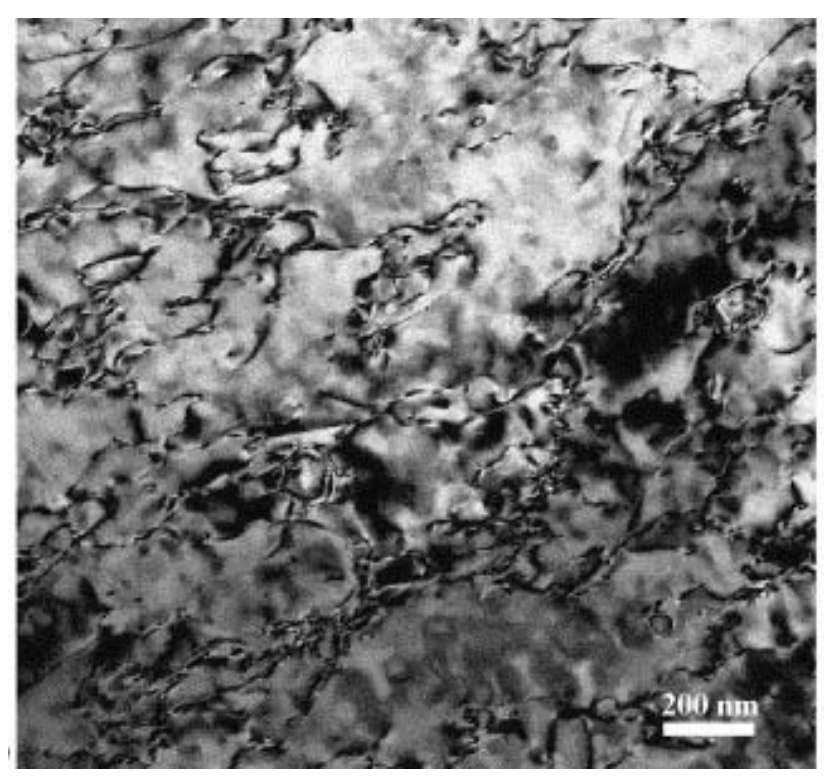

Fig. 2 Transmission electron micrograph showing the microstructure of the TMAZ of a 5251 FS weld (from [2]).

The relationship between the increment in CRSS due to dislocations $\Delta \tau_{\mathrm{D}}$ and the total dislocation density $\rho$ can be expressed by $[18,19]$ :

$$
\Delta \tau_{\mathrm{D}}=\alpha_{1} G b \sqrt{ } \rho
$$

where $\alpha_{2}$ is about 0.3 . Dislocation densities are often mentioned as being a significant factor in local strength of FS welds and FS processed metals. However, an assessment of TEM micrographs in the papers cited in this and previous works by the authors indicates that the dislocation densities seen in FS welds are limited. The highest dislocation density observed in published TEM work is about $0.6 \times 10^{14}$ $\mathrm{m}^{-2}$ (see Fig. 2 which shows dislocations in an FS weld of a 5251Al-2.2Mg-0.2Mn alloy). This dislocation density provides $\Delta \tau_{\mathrm{D}}=13 \mathrm{MPa}$, providing a contribution to the strength of $\sim 40 \mathrm{MPa}$. Seeing that this is an upper limit based on the highest dislocation density seen in published micrographs, we 
have to conclude that contributions due to dislocations to the yield strength are low. This analysis also shows that the combination of temperature and deformation in FS processing is unlikely to lead to dislocation densities higher than the ones measured here. That is, dynamic recovery and ultimately recrystallisation will cause a limitation in the amount of dislocations. In the recrystallised central zone dislocations are virtually absent. As a comparison, dislocation densities in Al alloys cold rolled to 10\% reduction are about $4 \times 10^{14} \mathrm{~m}^{-2}$ [19], i.e., nearly 10 times larger.

In Eq. 1, the influence of local crystallographic texture on local yield strength is described through the factor $M$. If it is assumed that all grains experience the same strain, this factor can be calculated using the Bishop-Hill analysis [20]. We calculated $M$ from grain orientation data obtained from Electron Backscatter Diffraction data on two FS welds of $3 \mathrm{~mm}$ plate: one was a symmetric weld of 2024-T3 with the welding direction parallel to the rolling direction of the two welded plates, and the second weld was asymmetric where one 2024-T3 plate with rolling direction parallel to the welding direction was welded to a 2024-T6 plate with rolling direction normal to the welding direction. The $M$ factors of the symmetric plate (Fig. 3) are broadly symmetric around the weld centre line, with a value of around 3.1 in the recrystallised central area, rising to 3.25 in the plate well away from the rotating tool. A sharp change in $M$ between about 3 and $4 \mathrm{~mm}$ distance from the weld centre line coincides with the border of the recrystallised zone. The asymmetric plate shows similar behaviour for the retreating side and the recrystallised centre, and an $M$ value of about 3 for the advancing side where the rolling direction was normal to the welding direction. The variations in $M$ values for these plates can be explained from the initial rolling textures and the recrystallisation reaction. The changes in $M$ due to recrystallisation are about $5 \%$ and hence differences in strength due to changes in texture can also be about $5 \%$. This serves to show that any model for local strength that aspires to reach similar accuracies should include an analysis of texture.

\section{Future directions for microstructure and strength predictions of FSW and FSP alloys.}

A range of researchers have attempted to provide integrated models for the microstructural evolution and strength of FS welds [17,21,22,23]. These models generally are able to provide trend predictions of strength and we will here assess some of the limitations of existing models and consider improvements.

\section{Coupling of heat effects and microstructure development.}

Microstructural evolution continually modifies the constitutive material properties and response, but this is not included in existing models. Particularly notable here are the effects of transformations on conductivity and heat generation in the material. The heat conductivity of aluminium alloys depends significantly on the microstructure, in particular the amount of dissolved atoms in the fcc Al-rich phase [24]. In typical heat treatable alloys such as 2024 and 7050, the thermal conductivity at room temperature can vary by $20 \%$ depending on the amount of elements dissolved. For an approximation, distance scales with conductivity, and from strength predictions (see e.g., [3]) it is estimated that a variation in thermal conductivity of $20 \%$ can cause a temperature change in the HAZ of about $25 \mathrm{~K}$. Such a temperature change can cause a misprediction of strength of up to about $40 \mathrm{MPa}$. A further coupling between models is caused by the heat evolution caused by the reaction in the material. Precipitation and dissolution reactions especially can cause a heat evolution that has a significant impact on the local temperature. For example, the formation of S phase in $2024 \mathrm{Al}$ generates an 
exothermic heat of $18 \mathrm{~J} / \mathrm{g}$ [25], which equates to a temperature rise of the alloy of $21 \mathrm{~K}$. Such a temperature change can cause a misprediction of strength of up to $35 \mathrm{MPa}[3,5]$.

\section{Micro/nanostructural predictions of precipitates.}

In terms of micro/nanostructural predictions of precipitates, the complexity of the thermomechanical processes needs to be explicitly taken into account in the models. A list of key issues for future models includes:

- The effect of rapid temperature changes. Important challenges include the description of the transition between dissolution and coarsening [26], the precipitation during cooling with possible re-nucleation of phases.

- Multi-particle and multi-nucleation site models. In fact, the resulting microstructure of a given location in an FSW weld is invariably a mixture of several phases of different thermodynamic stability (from co-clusters / GP zones up to equilibrium precipitates) located either homogeneously or on various structural defects (dislocations, grain boundaries, dispersoids). It is a major challenge to predict the coupling between these precipitate families, which can itself show several levels of complexity: either simply through the level of the average solid solution, with spatial coupling (precipitate-free zones around coarse precipitates, unaffected solid solution further away), or with cascade effects (one phase serving as a nucleus for the subsequent phase).

- Coupling with plastic deformation. Apart from the classical situation of precipitation in a plastically deformed material, where dislocations act as preferential nucleation sites and fast diffusion paths, the full coupling has many other possible effects: solute atoms transport via Cottrell atmospheres, precipitate morphology change due to constant shearing of the precipitates during their formation, sweeping or creation of excess vacancies, etc [34].

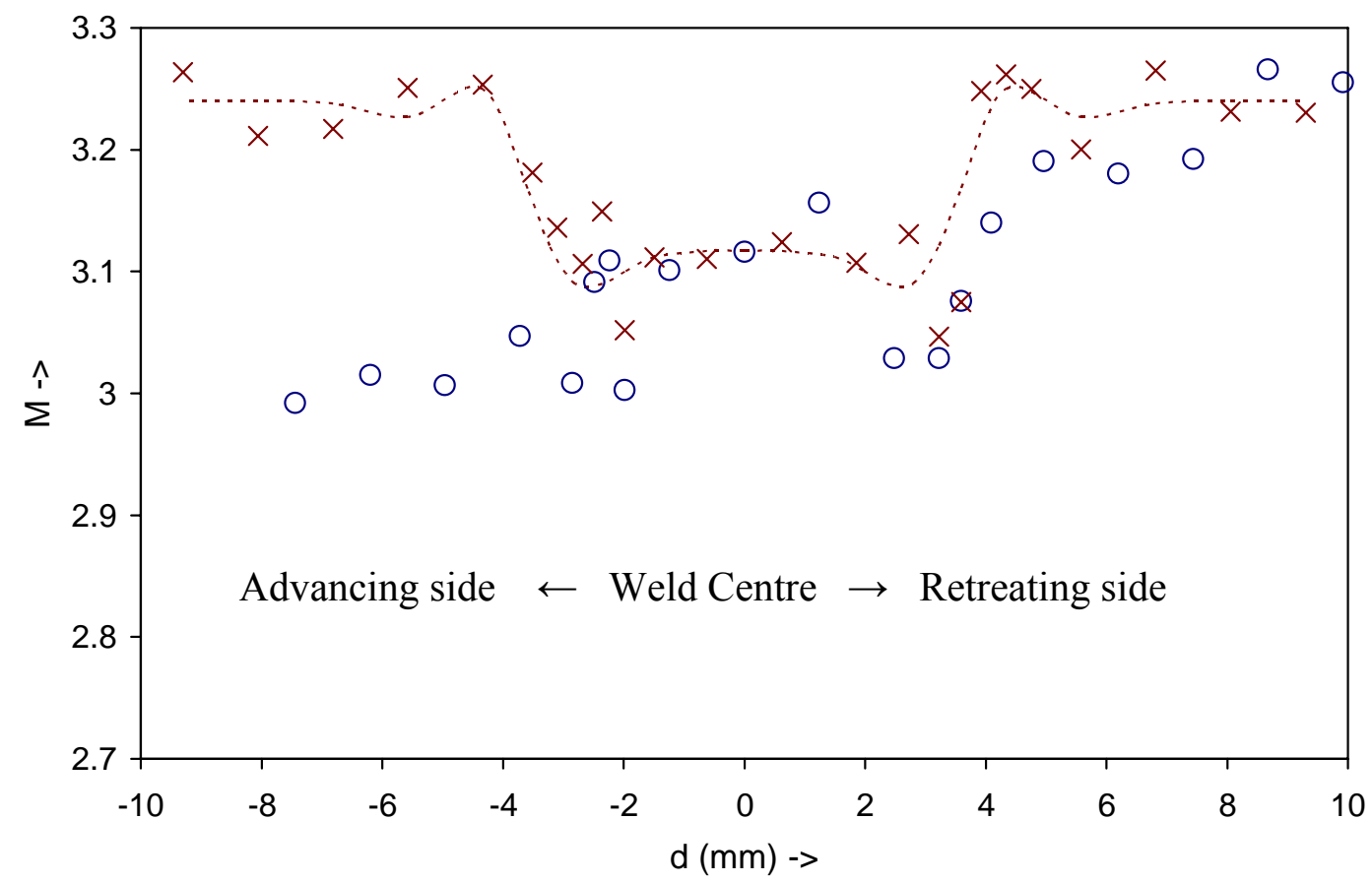

Fig. $3 M$ factor for the symmetric (×) and asymmetric (o) 2024 weld as a function of the distance to the weld centre, $d$. The dotted line shows a trend for the symmetric weld. 


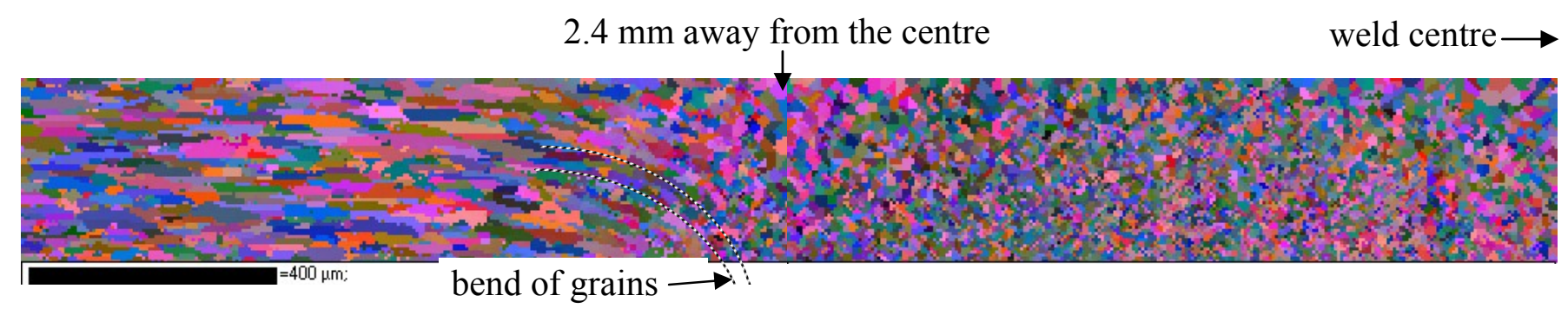

Fig. 4 EBSD (OIM) of a section of a $3 \mathrm{~mm}$ thick $20324 \mathrm{FS}$ weld, showing the bend in the heavily distorted grains just outside the recrystallised zone.

Dislocation densities, grain size and substructure.

Future improvements may further be found by explicitly predicting dislocation densities, grain size, and substructure of welds, and using those to predict strength. An approximate model for predictions of grain size in the recrystallised zone has recently been suggested [15,27], and we would here like to demonstrate that progress in predicting dislocation densities may be possible. Whilst the contribution of dislocations to the strength is limited, they nevertheless have some importance as the temperature for onset of recrystallisation will be close to that of the maximum detrimental effect of precipitate evolution (coarsening, dissolution). Hence, the peak strength contribution due to dislocation density will generally coincide with the minimum in contribution due to precipitate strengthening. Thus, dislocations can have a valuable contribution in counteracting the (often dominant) effect of precipitation strengthening. As a starting point for modelling, we may consider the density of geometrically necessary dislocations (GNDs) related to the deformation predicted by flow models. Detailed treatments of GNDs are available (see e.g., [18,28,29]), and in a simplified form the density of GNDs $\left(\rho_{\mathrm{GND}}\right)$ is related to the effective plastic strain gradient $\eta^{\mathrm{p}}$ by $[18,30]$ :

$$
\rho_{G N D}=\bar{r} \frac{\eta^{p}}{b}
$$

where $\bar{r}$ is the Nye factor which is around 1.9 for fcc polycrystals [29]. We may apply this to the bending of grains seen in cross sections of FS welds, as illustrated in Fig 4 . This results in $\rho_{\mathrm{GND}}=$ $0.2 \times 10^{14} \mathrm{~m}^{-2}$, whilst lattice rotations of about $0.5 \%$ m within one grain in a $25 \mathrm{~mm}$ thick 2195 Al-alloy FS weld [31] indicate $\rho_{\mathrm{GND}}=0.3 \times 10^{14} \mathrm{~m}^{-2}$. The former calculation only takes account of the final bending distortion of the grain in one plane and thus neglects GNDs introduced in the course of the passage of the tool which may have involved other grain distortions. The present assessment of $\rho_{\mathrm{GND}}$ shows an encouraging agreement with estimates from direct observation (see e.g. Fig 2).

Validation, limits of viability and feasibility.

In terms of strength predictions for a given predicted micro/nano structure, existing models provide a reasonable estimate of yield strength [3,6,32,33]. A better understanding of superposition laws would still be welcome in situations where a large number of different obstacles to dislocations are present (forest dislocations, several types of precipitate phases, small grains). The situation is much less advanced in terms of damage tolerant properties such as ultimate tensile strength, ductility, and 
toughness. These properties require large improvements in the existing models to handle the complexity of the microstructure. Particularly interesting trends in recent work include a better understanding of the effect of precipitation on work hardening [34], and accounting of the effect of multiple families of hard particles on ductile fracture, resulting in an improvement in the prediction of the fracture path (trans or inter-granular) as a function of microstructural features [35].

Addition of more detailed model elements and addition of interactions between elements of models, will cause ever steeper rises in model complexity and computational demands, and a complete model is likely to proof unviable and possibly an utopy. Thus, different levels of simplification will still need to be used in the foreseeable future. These should be adapted to the objective of the modelling effort. For instance, a model for the optimisation of process parameters (tool speed, tool geometry) needs to be fully integrated but may include more phenomenological parameters as compared to a model where the aim is to optimize the alloy composition to offer an optimal response to FS welding.

\section{Possible ways of improving the strength of FSWs}

In improving FS welds made of a precipitation hardening alloy, maximizing the yield strength of the weakest zone of a weld is particularly important. In the zone where the highest level of deformation takes place (the nugget), one can expect that near full solutionising is achieved during FS welding. Also, substantial strength recovery is possible in this zone due to re-precipitation of low-temperature phases such as co-clusters / GP zones. The weak zone is almost invariably adjacent to the nugget where the temperature reached is such that stable precipitates have coarsened to a state where they provide little contribution to the strength, whilst their volume fraction is such that they impede strength recovery by re-precipitation. Optimisation of strength of FS welds of heat treatable alloys can be sought with several complementary strategies. For example, minimizing the duration of the temperature spike (for instance by cooling of the weld or increasing welding speed) will generally increase the strength in the weakest section of the welds [36] both by limiting the time available for coarsening of phases and by reducing the time at the nose of the TTT diagram where detrimental precipitates form during cooling. Alternatively, we can attempt to modify alloy chemistry to provide precipitates that are more resistant to coarsening. One can think of alloys strengthened by $\Omega$ phase or by adding an additional stable strengthening phase in the form of $\mathrm{Al}_{3}(\mathrm{Zr}, \mathrm{Sc})$ particles. Volume fractions and size would need to be optimized to provide significant strength, while not impeding the formability of the material in the nugget. In terms of the kinetics of phase formation during cooling, the TTT diagram needs to be translated to longer times, especially in the presence of deformation. This may be achieved by alloy modifications that lead to precipitates that are less susceptible to nucleation on dislocations and by a reduced diffusion coefficient. Also, increased alloy purity will generally lead to reduced quench sensitivity. To optimise the potential for post weld heat treatment, a large difference between the solubility at the nose of the TTT diagram and the ageing temperature will maximize the potential for strength recovery after cooling.

In parallel, it is of interest to discuss the potential for post-weld precipitation treatments. These have been studied in some detail in the literature, and their results are uneven [32,37,38]. The challenge is often to recover some strength in the weakest zone, which is often very difficult because this location is close to thermodynamic equilibrium. Three types of heat treatments can be applied: 
- Natural ageing has the advantage of not affecting the properties of the base material. However it does not decrease the level of internal stresses and has little chance of significantly improving the strength of the weak zone except if one achieves a large enough supersaturation.

- Artificial ageing is often found to have a detrimental effect. Even though a well solutionized nugget reaches an interesting strength level, the strength of the weak zone usually decreases further because the solute supersaturation is too small to allow re-precipitation of hardening phases. Some improvement may be possible in specific systems with low-temperature heat treatments. However, it seems unlikely that a high potential exists for such treatments (which in addition are quite costly).

- Full heat treatment including solutionizing and ageing may be possible in some specific cases involving components of limited size. However, a number of problems may be encountered: one has to limit abnormal grain growth in the weld nugget; a compromise between quench-induced precipitation and internal stresses has to be found (as no uniform post-quench stretching is possible the relief of internal stresses is not possible), and the absence of dislocations may in some cases (e.g,. Al-Li-Cu alloys) impede the hardening potential. In the case of quenching of a complex geometry, part distortion may also be an issue.

\section{Strength and the balance of properties of FSWs}

Weld optimisation is a multi-objective exercise in which several strategies may be followed. If we just focus on strength, strategies may include:

- maximizing the lowest local strength present in any part of the weld

- minimizing the strength differential between the weld and the base material

- maximizing the ultimate tensile strength, ductility or other properties of the weld

The relevance of the various strategies is dependent on design options (e.g., local load on the weld as compared to the nearby plate) and required subsequent plastic forming.

It is clear that global properties of the weld are not governed by the just the local properties of the weakest zone, but by the combination of several zones of different strength and their geometric characteristics. One interesting case is the ductility of an FS welded assembly. The most unfavourable case is that of a very strong base material and a weak zone for which the ultimate tensile strength $\left(\sigma_{\mathrm{u}-\mathrm{w}}\right)$ is lower than the yield strength of the base material $\left(\sigma_{\mathrm{y}-\mathrm{b}}\right)[2]$. In this case, the weld will show ductile failure before the base material has experienced full plastic deformation, and the global ductility of the part is extremely low (as well as the energy dissipated before fracture) Thus, an optimization of the ratio $\sigma_{\mathrm{u}-\mathrm{w}} / \sigma_{\mathrm{y}-\mathrm{b}}$ may be important in terms of weld design.

The tendency for plastic strain localization also has important consequences on the fracture of welds. Depending on the characteristics of the weak zone (width to thickness ratio, yield strength differential), the stress state experienced can be vastly different. The stress triaxiality could be more than doubled in the weak zone leading to early ductile fracture, especially since the weak zone usually contains a large fraction of coarse precipitates on grain boundaries which are effective nucleation sites for cavities[39]. Moreover, actions that can be taken to improve the strength of an FSW may lead to detrimental consequences on other properties. For instance, welding at cold temperatures may lead to very good strength, but to high internal stresses and small defects which can decrease fracture and fatigue properties. The resistance to corrosion and stress corrosion of FSW welds is also an important issue, with processing requirements that can contradict strength optimisation. 


\section{Conclusions}

The factors influencing the strength of FS welded and FS processed materials have been assessed through comparison of theoretical models for strengthening of polycrystalline materials, and data on FS welds and FS processed materials. This showed that stored dislocation densities are substantially lower than in cold worked alloys and hardening by stored dislocations is generally limited to 40MPa. Grain size strengthening is in most cases less than $10 \mathrm{MPa}$, unless special cooling measures cause sub micron grain sizes. In heat treatable alloys, precipitation hardening is the dominant mechanism responsible for strength and local strength variations. Published models for strengthening of FS welds make a range of simplifying assumption, causing uncertainties in the predictions of up to 50MPa. Improvements likely to improve weld strength include modification of the alloy chemistry and accelerated weld cooling, both with the aim of suppressing precipitation during the cooling phase or coarsening of precipitates

\section{Acknowledgements}

Boeing is gratefully acknowledged for providing the $2024 \mathrm{FS}$ welds.

[1] C. Dawes, W. Thomas, TWI Bull. 6 (1995) 124

\section{References}

[2] C. Genevois, A. Deschamps, P. Vacher, Mater Sci Eng A 415 (2006) 162.

[3] M.J. Starink, S.C. Wang, I. Sinclair, in 'Friction Stir Welding and Processing III', Ed. Kumar V. Jata, M.W. Mahoney, R.S. Mishra (TMS, Warrendale, PA, USA, 2005) pp. 233-240

[4] P. Vilaca, L. Quintino, J.F. dos Santos, R. Zettler, S. Sheikhi, Mater Sci Eng A 445-446 (2007) 501

[5] D.P.P. Booth, M.J. Starink, I. Sinclair, Mater Sci Techn 23 (2007) 276

[6] S.C. Wang, F. Lefebvre, J.L. Yan, I. Sinclair, M.J. Starink, Mater Sci Eng A, 431 (2006) 123

[7] M.J. Starink, S.C. Wang, Acta Mater. 51 (2003) 5131

[8] K. Marthinsen, E. Nes, Mater. Sci. Eng. A 234-236 (1997) 1095

[9] E. Nes, T. Pettersen, K. Marthinsen, Scr. Mater. 43 (2000) 55

[10] L.B. Johannes, I. Charit, R.S. Mishra, Ravi Verma, Mater Sci Eng A, 464 (2007) 351

[11] C.A.W. Olea, L. Roldo, J.F. dos Santos, T.R. Strohaecker, Mater Sci Eng A, 454-455 (2007) 52.

[12] R.M. Leal, A. Loureiro, Mater Design, in press (2007)

[13] P. Cavaliere, P.P. De Marco, Mater Sci Eng: A, 462 (2007) 206.

[14] C.I. Chang, X.H. Du, J.C. Huang, Scr Mater, 57 (2007) 209.

[15] D.C. Hofmann, K.S. Vecchio, Mater Sci Eng A, 465 (2007) 165.

[16] Jian-Qing Su, T.W. Nelson, C.J. Sterling, Mater Sci Eng A, 405 (2005) 277.

[17] O. Frigaard, O. Grong, O.T. Midling, Metall. Mater. Trans. A 32A (2001) 1189

[18] M.F. Ashby, Phil. Mag. 21 (1970) 399

[19] S.C. Wang, Z. Zhu, M.J. Starink, J. Microscopy, 217 (2005) 174

[20] J.F.W. Bishop, R. Hill, Phil. Mag. 42 (1951) 414

[21] H.R. Shercliff, M.J. Russell, A. Taylor, T.L. Dickerson, Méc. Ind. 6 (2005) 25

[22] N. Kamp, A. Sullivan, J.D. Robson, Mater Sci Eng: A, in press (2007).

[23] O.R. Myhr, O. Grong, H.G. Fjaer, C.D. Marioara, Acta Mater. 52 (2004) 4997

[24] M.J. Starink, X.M. Li, Metall Mater Trans A, 34 (2003) 899

[25] I.N. Khan, M.J. Starink, J. Yan, Mater Sci Eng A, 472 (2008) 66

[26] M. Nicolas, A. Deschamps, Acta Mater 51 (2003) 6077

[27] G. Buffa, J. Hua, R. Shivpuri, L. Fratini, Mater Sci Eng A, 419 (2006) 381

[28] E. Van der Giessen, A. Needleman, Scripta Mater 48 (2003) 127

[29] A. Arsenlis, D.M. Parks, Acta Mater, 47 (1999) 1597.

[30] F. Zhang, R. Saha, Y. Huang, W.D. Nix, K.C. Hwang, S. Qu, M. Li, Int J Plasticity, 23 (2007) 25 
[31] P.B. Prangnell, C.P. Heason, Acta Mater 53 (2005) 3179.

[32] Genevois C, Deschamps A, Denquin A, Doisneau Cottignies B. Acta Mater 53 (2005) 2447

[33] I.N. Khan, M.J. Starink, S.C. Wang, I. Sinclair, submitted

[34] C. Genevois, D. Fabregue, A. Deschamps, W.J. Poole, Mater Sci Eng A, 441 (2006) 39.

[35] T. Pardoen, D. Dumont, A. Deschamps, Y. Brechet Y. J Mech Phys Solids 51 (2003) 637

[36] M. Dumont, A. Steuwer, A. Deschamps, M. Peel, P.J. Withers, Acta Mater 54 (2006) 4793

[37] K.V. Jata, K.K. Sankaran, J.J. Ruschau. Metall Mater Trans A, 31 (2000) 2181

[38] Y.S. Sato, H. Kokawa. Metall Mater Trans A, 32 (2001) 3033 